\title{
STABILITY OF STATICALLY INDEFINITE PHYSICALY NONLINEAR TIMBER STRUCTURAL SYSTEMS
}

\author{
Yemelyanov Sergey Gennadyevich, Ekaterina Gennadievna Pakhomova, Ksenia Olegovna Dubrakova*, \\ Sergey Valerievich Dubrakov
}

Southwest State University, Kursk, Russia

The procedure for determining the critical stability parameters of wood constructive systems is given, taking into account the features of the deformation stage in which the compressed elements are located. The dependence of critical parameters on the loading scheme and frame dimensions is determined. The order and results of experimental studies of a single-span structural system of wood are given. It was revealed that taking into account the features of the deformation stage, in which the compressed frame racks are located, will lead to an increase in the critical force value. It is concluded that the proposed criterion for assessing the stability of compressed wood core elements makes it relatively easy to assess the resource resistance of such elements, taking into account the effect of the level of operating stresses on the stiffness value.

Key words: subsidence soils, framerod systems, performance, stability, emergency

\section{INTRODUCTION}

At designing, stability analysis of structural systems often deals with analysis of single compressed or bentcompressed elements and interaction of element is not taken in account. At the same time an important meaning has axial compressing force acting to rod element. However, in majority cases, for example, at passive bifurcation, this contradicts to phenomena of buckling and can lead to irreversible consequences [3]. Thus, it is necessary to develop buckling criterion for different timber structural systems operating under power loading. Such criterion should allow describing of a structural system behavior as a whole and determine critical force value taking in account affecting of neighbor elements.

\section{DETERMINING EQUATIONS}

When we calculate nonlinear and nonstationary deforming statically indefinite timber structures, the integral assessment method can be applied. This method allows linearizing of the problem and fixing of nonstationary deformation features [1-12].

Different points of an element cross section, subjected nonhomogeneous stress-strain state, has different values of stresses. At compressing normal stresses are equal for constant cross section until buckling process. At the same time in the different elements of structural system these stresses differ. Nonlinearity of material deforming leads to difference between deformation modulus for elements with different stress values and, consequently, create additional mathematic difficulties.

It gives possibility using method suggested by $A$. R. Rzhanitsyn [7]. This method allows accounting complex timber deforming in time, using division of deforming process into three parts and substituting complex nonlinear dependency between stresses and strains by partially linear dependencies, that satisfies to continuity condition for deformations, velocities of deformations and stresses for all stages.

Characteristic features of mentioned stages for timber are in follows [7]:

1. For the first stage of deforming, creep is reversible, satisfies to general positions of linear creep theory;

2. At the second stage (stationary creep) deformation occurs with constant velocity, but deformations are irreversible;

3. The third stage characterizes increasing of irreversible deformations.

Figure 1 shows creep curves for different stress levels.

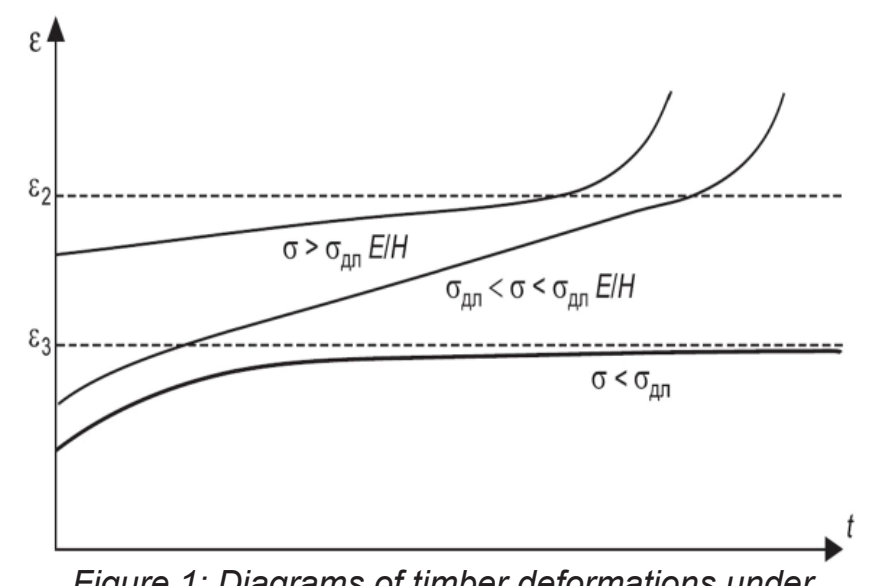

Figure 1: Diagrams of timber deformations under long-term loading depending on stress level

In order to describe deformation process, we apply the following equations [7]:

- First stage - stage of linear creep, which is expressed by general simplified relationship of linear creep:

$n E_{0} \dot{\varepsilon}+H \varepsilon=\sigma+n \dot{\sigma}$ 
- Second stage is stationary creep:

$n E_{0} \dot{\varepsilon}=\sigma+n \dot{\sigma}-\sigma_{\partial л}$

- Third stage is one that characterized by deformation velocity increases:

\section{$n E_{0} \dot{\varepsilon}-B \varepsilon=\sigma+n \dot{\sigma}-\sigma_{п \Pi}$}

Let us consider timber onespan frame in which the first leg loaded with concentrated axial force $\alpha P_{c r}$, and second one - with $P_{c r}$ (fig. 2). Let us determine length factor for considering frame for different multiplier values $\alpha$ for two cases. At considering of the frame, in the first case modulus values for legs are constant and accepted according to regulatory documents, in the second case we take in account deformation modulus changing in dependence on acting stress value.

Figure 2 presents general and equivalent systems of the displacement method for considered frame.

a)

b)

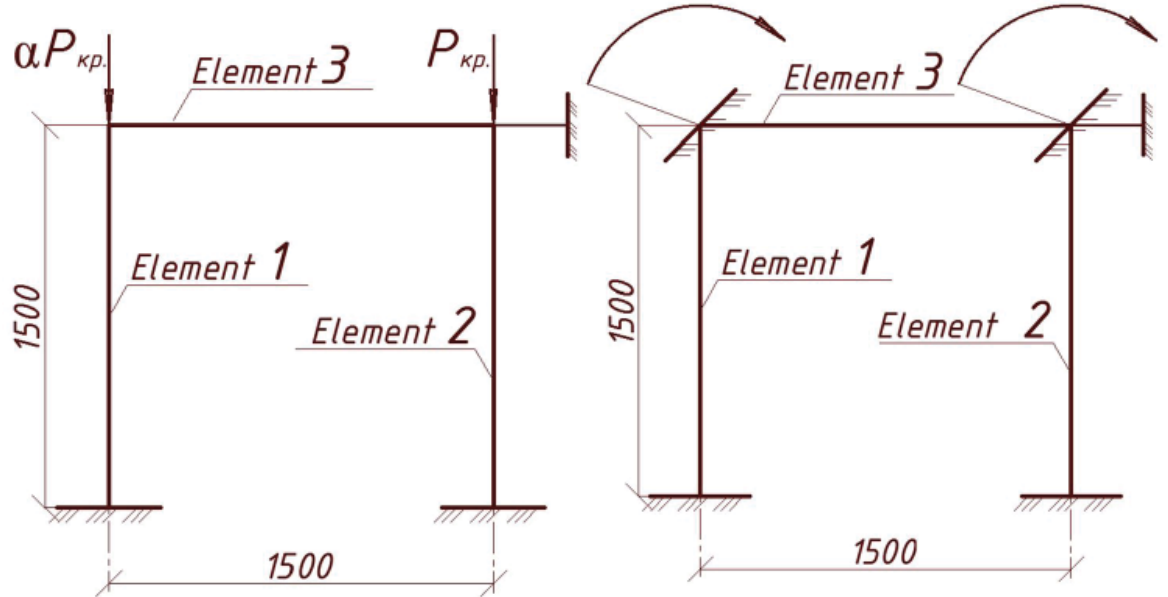

c)

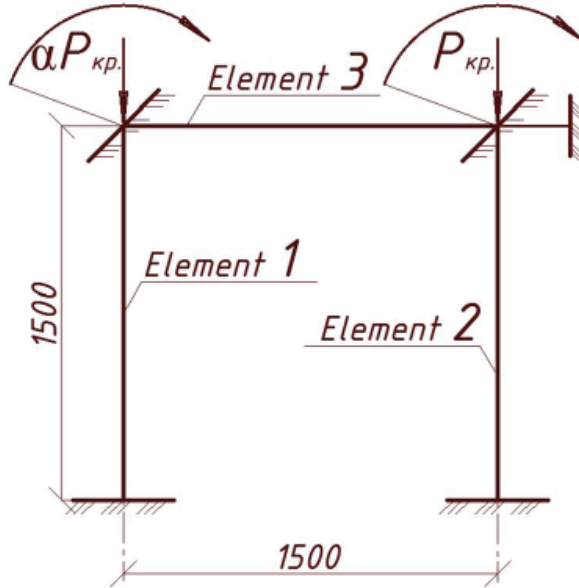

Figure 2: Calculation scheme of the frame (a), general (b) and equivalent (c) systems of the displacement method

Determinant of the system (4) can be found from the following expression:

Det $=\left(4 \cdot i_{1} \cdot \varphi_{2}\left(v_{1}\right)+4 \cdot i_{3}\right) \cdot\left(4 \cdot i_{2} \cdot \varphi_{2}\left(v_{2}\right)+4 \cdot i_{3}\right)-4 \cdot i_{3}^{2}$

Transforming expression (5) we obtain characteristic equation for length factor:

$4 \cdot i_{1} \cdot i_{2} \cdot \varphi_{2}\left(v_{1}\right) \cdot \varphi_{2}\left(v_{2}\right)+4 \cdot i_{2} \cdot i_{3} \cdot \varphi_{2}\left(v_{2}\right)+4 \cdot i_{1} \cdot i_{3} \cdot \varphi_{2}\left(v_{1}\right)+3 \cdot i_{3}^{2}=0$

Considering the frame in the second case, reduced stiffness is determined in regards to stresses level in the legs [6]:

$B_{\text {дл }}\left(t_{0}, t\right)=I \cdot\left[\frac{\varepsilon\left(t_{0}\right)\left(1+b\left(t-t_{0}\right)^{0.21}\right)}{\sigma(t)}+\sum_{i=1}^{k} \frac{\Delta \varepsilon_{i}}{\sigma(t)}\left(1+b\left(t-t_{i}\right)^{0.21}\right)\right]^{-1}$

where $\mathrm{b}$ is parameter, that depends on humidity of timber $(\mathrm{W})$ :

$b=\frac{10^{-2}}{0.735-0.02086 W}$

Load for each stage was constant.

In the second stage of deforming formula for stiffness of frame elements takes the form:

$B_{\partial л}\left(t_{0}, t\right)=I \cdot\left[\frac{\sigma_{\partial л}}{H \sigma(t)}+\frac{\sigma_{0}-\sigma_{\partial л}}{n E_{0} \sigma(t)}\left(t-t_{1}\right)+\sum_{i=1}^{k} \frac{\Delta \sigma_{i}}{\sigma(t) n E_{0}}\left(t-t_{i}\right)\right]^{-1}$

where $E_{0}$ is instantaneous initial deformation modulus; $E_{0}=1.48 \cdot 10^{4} \mathrm{MPa}[6] ; \varepsilon$ is current relative strain; 
In the third case stiffness of the frame legs at constant stresses can be determined from expression:

$B_{\partial л}\left(t_{0}, t\right)=I \cdot\left[\frac{\sigma-\sigma_{\partial \eta}}{B \sigma} e^{\frac{B\left(t-t_{2}\right)}{n E_{0}}}-\frac{\sigma-\sigma_{п \Pi}}{B \sigma}\right]^{-1}$

where $\sigma_{п п}$ is short-term strength; $\sigma_{п п}=22,0 \mathrm{MPa}$.

Using Euler formula, let us evaluate stability of centrally compressed rod element of rectangular cross section of timber structural system:

$P_{c r}=\frac{v^{2} \cdot B_{\partial л}\left(t_{0}, t\right)}{l^{2}}$

where $v=\pi / \varphi$ is coefficient taking in account influence of axial force to buckling.

From equation (11) we determine coefficient's value $v$ taking in account stresses acting in centrally compressed rod of the frame:

$v=\lambda \cdot \sqrt{\frac{\sigma}{B_{\partial л}\left(t_{0}, t\right)}}$

Transition into second stage of deforming occurs for stress value $\sigma_{п п}=22 \mathrm{MPa}$ [7]. Consequently, expression for determining of critical parameter $v_{c r}$ takes the form:

$v_{c r}=\lambda \cdot \sqrt{\frac{\sigma_{\text {пा }}}{B_{\text {дл }}\left(t_{0}, t\right)}}$

If calculated value of coefficient, accounting influence of axial force to buckling, is less than its critical value $\left(v \leq v_{c r}\right)$, then loss of stability occurs at the first stage of deforming and there is not necessity to take in account stresses in elements of a structural system. Figure 3 shows diagram of dependency for critical coefficient value $v_{c r}$ from flexibility of compressed element, that illustrates relationships (13).

$v_{c r}$

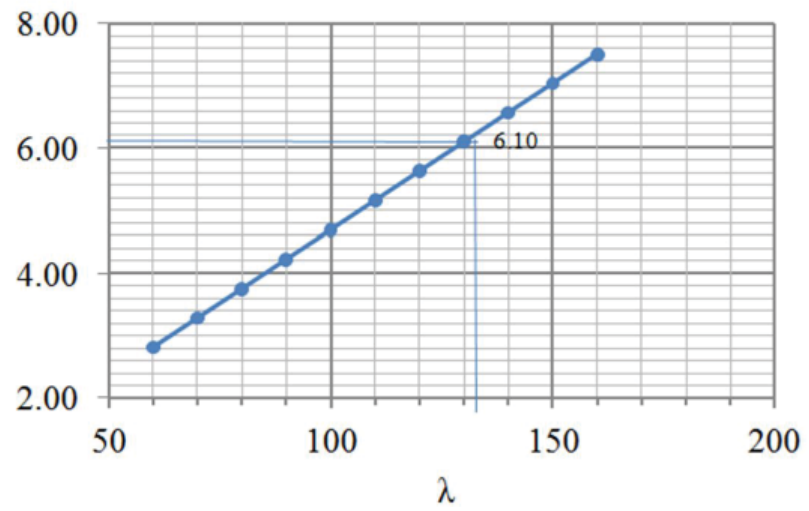

Figure 3: Diagram of dependency for critical coefficient value $v_{\text {cr. }}$ from flexibility of compressed element $\lambda$

Analyzing this diagram we conclude that timber structural elements with flexibility more than 140 loss stability at the first deforming stage, consequently stress level does not affect to critical force value.

\section{QUANTITATIVE ANALYSIS}

Using mentioned equations we found critical parameters. For considered frame we determined coefficients of secular stability equation, values of special functions of the displacement method, length factors for each compressed leg. Figure 4 presents results of such calculation.

Assessment of elements' length factors is interest. Consequently, critical force values, taking in account complexity of timber deforming in time at process division into three stage.

$v^{2}$

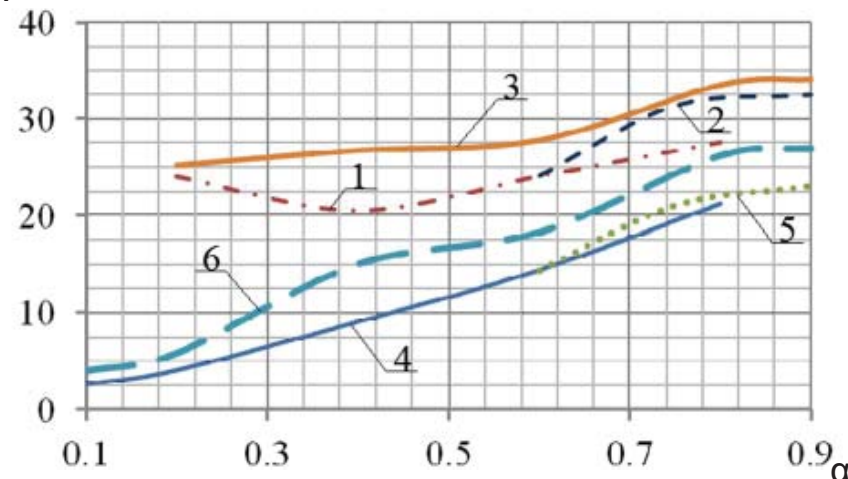

Figure 4: Changing of coefficient $v^{2}$ depending on multiplier to load $\alpha: 1,4-$ at calculation of structural system taking in account constant value of timber modulus; 2, 5- at modulus $E$ changing, during

elements' transition into second deforming stage;3, 6 - experimental values $v^{2}$ for legs 2 and 1 respectively Taking in account influence of stresses to frame element's stiffness is necessary, if load multiplier for the first leg is $\alpha \geq 0,75$, if it takes less value than both legs buckling before second deforming stage is reached. This approach increases critical force value of the most loaded leg for $7 \%$, and for less loaded leg for $5 \%$.

Qualitative and quantitative assessment of the presented analytical dependencies is conried out for which of laboratory of department of civil engineering (SWSU). Figure 5 shows scheme of experiment and general view of experimental equipment. Set of prames that consist of 5 special with girder's and leg's cross sections $50 \times 40$ $\mathrm{mm}$, are subjected to central compression using special methodic, suggested by author.

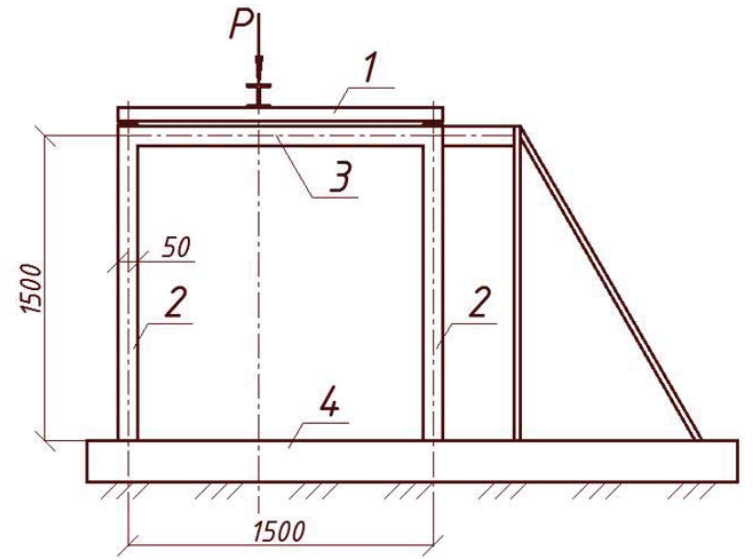




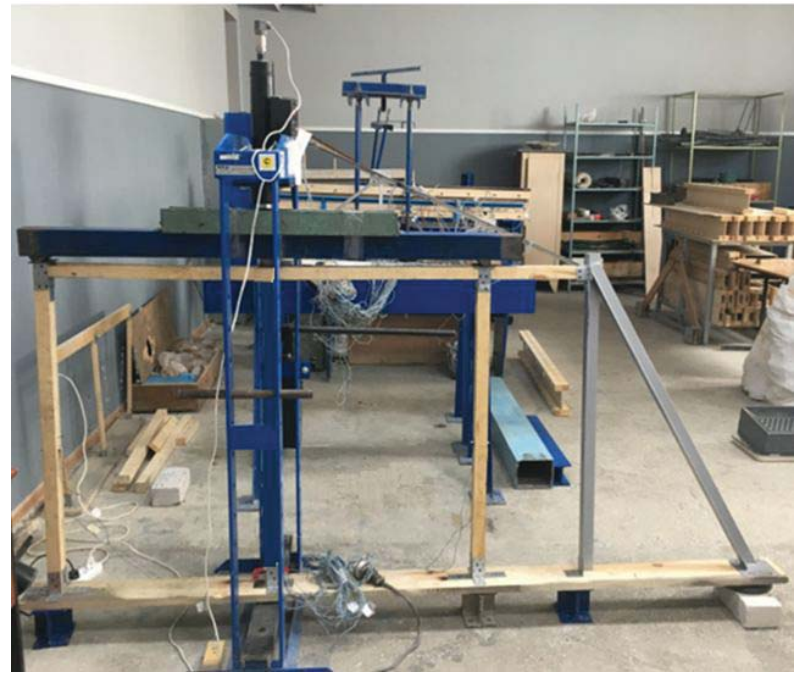

Figure 5: Scheme (a) and general view of experiment

(b) for frame specimen: 1 - distributive; 2 - frame legs; 3 - girder; 4 - support feam

Satisfactorily comsidence of theoretical critical force values with experiment data for centrally compressed rod proves reliability of the theoretical model used in calculations.

\section{CONCLUSIONS}

Proposed criterion for stability assessment of compressed rod elements of timber structural systems allows us evaluate power resistance of such elements taking in account influence of stress level to flexural stiffness values. Analysis of oftained results shows that taking in account features of deforming stages, in which compressed frame legs operate, leads to increasing of critical force value.

\section{REFERENCES}

1. Alexandrov, A.V. Criteria for identifying the most dangerous elements and their use in problems of structural stability / A.V. Alexandrov, A.V. Matveev // train Safety: Tr. 4th science.-prakt. Conf. - M.: MIIT, 2003. - Page III-1 - III-2.

2. Alexandrov, A.V. On the calculation of rod structures for stability / A.V. Alexandrov, V. I. Tra-vush, A.V. Matveev // Industrial and civil construction. - 2002. — № 3. - P. 16-20.
3. Alexandrov, A.V. Study of the stability of the arched covering structures of the hall using the criteria for identifying the most dangerous elements / A.V. Alexandrov, V. I. Travush, A.V. Matveev //Bulletin of the Department of construction Sciences RAASN. 2004. - Issue. 8. - P. 14-21.

4. Alexandrov, A.V. the Role of individual elements of the core system in the loss of stability /A.V. Alexandrov // Herald of MIIT. - 2001. - Issue. 5. - P. 46.

5. Khaustov, V., Kruglova, L., Bredikhina, N., \& Guseinov, T. [2019]. The impact of flooding on the operational reliability of real estate in the Kursk region. Journal of Applied Engineering Science, 17(2), 213216.

6. Matveev, A.V. Some questions of creation of the specialized software complex for the analysis of bridge structures / A.V. Matveev // Vestnik Miita. - 2002. - Issue. 7. - P. 76-83

7. Pyatikrestovskiy, K. P. Nonlinear deformation statically indeterminate R-data structures/ K. P. Pyatikrestovskiy, H. S. Chugunov // news of higher educational institutions. Construction. - 2013. - № 11-12. - P. 21-30.

8. Pyatikrestovsky, K. P. Nonlinear methods of mechanics in the design of modern wooden struc-tures / K. P. Pyatikrestovsky. - Moscow: MGSU, 2014. $-320 \mathrm{p}$.

9. Pyatikrestovsky, K. P. On programming a nonlinear method of calculation of wooden struc-tures / K. P. Pyatikrestovsky, V. I. Travush // Academia. Architecture and construction. - 2015. — № 2. - Pp. 115119.

10. Travush, V. I. Experimental and theoretical study of the strength and stability of compressed wood rods under force and environmental impact/V. I. Travush, V. I. Kolchunov, K. O. Dmitrie-va//proceedings of higher educational institutions. technology of textile industry. - 2016. - №3. P. 280-285.

11. Travush, V. I. Stability of compressed rods made of wood with simultaneous manifestation of force and environmental impact/V. I. Travush, V. I. Kolchunov, K. O. Dmitrie-VA//Construction me-chanics and calculation of structures. - 2016. - №2. P. 50-53.

12. Gennadyevich, Y. S., Pakhomova, E. G., \& Olegovna, D. K. [2019]. Reliability of RC frame-braced systems in dangerous geological conditions. Journal of Applied Engineering Science, 17(2), 245-250. 